\title{
S sentem \\ Leriche Syndrome Diagnosed Due to Polytrauma: a Case Report
}

\section{Genki Yoshimura}

Gifu University Hospital, Gifu, Advanced Critical Care Center

Ryo Kamidani ( $\nabla$ ryo.kami0125@gmail.com )

Gifu University School of Medicine Graduate School of Medicine: Gifu Daigaku Igakubu Daigakuin Igakukei Kenkyuka https://orcid.org/0000-0002-8478-9197

\section{Tomotaka Miura}

Gifu University Hospital, Gifu, Advanced Critical Care Centor

\section{Hideaki Oiwa}

Gifu University Hospital, Gifu, Advanced Critical Care Center

\section{Yosuke Mizuno}

Gifu University Hoapital, Gifu, Advanced Critical Care Center

\section{Ryu Yasuda}

Gifu University Hospital, Glfu, Advanced Critical Care Center

\section{Yuichiro Kitagawa}

Gifu University Hospital, Glfu, Advanced Critical Care Center

\section{Tetsuya Fukuta}

Gifu University Hospital, Glfu, Advanced Critical Care Center

\section{Takahito Miyake}

Gifu University Hospital, Gifu, Advanced Critical Care Center

\section{Haruka Okamoto}

Gifu University Hospital, Gifu, Advanced Critical Care Center

\section{Norihide Kanda}

Gifu University Hospital, Gifu, Advanced Critical Care Center

\section{Tomoaki Doi}

Gifu University Hospital, Gifu, Advanced Critical Care Center

\section{Hideshi Okada}

Gifu University Hospital, Gifu, Advanced Critical Care Center

\section{Takahiro Yoshida}

Gifu University Hospital, Gifu, Advanced Critical Care Center

\section{Shozo Yoshida}

Gifu University Hospital, Gifu, Advanced Critical Care Center

\section{Shinji Ogura}

Gifu University Hospital, Gifu, Advanced Critical Care Center 


\section{Case report}

Keywords: aortoiliac occlusive disease, conservative treatment, Leriche syndrome, Trauma

Posted Date: October 20th, 2021

DOI: https://doi.org/10.21203/rs.3.rs-966846/v1

License: (c) (1) This work is licensed under a Creative Commons Attribution 4.0 International License. Read Full License

Version of Record: A version of this preprint was published at International Journal of Emergency Medicine on February 4th, 2022. See the published version at https://doi.org/10.1186/s12245-022-00411$\mathrm{X}$. 


\section{Abstract}

\section{Background:}

Leriche syndrome is caused by atherosclerosis and is often characterized by symptoms such as intermittent claudication as well as numbness and coldness of the lower limbs. Its exact prevalence and incidence are unknown because it is a rare disease. We report a case of Leriche syndrome diagnosed incidentally on a trauma pan-scan computed tomography (CT).

\section{Case Presentation:}

A 61-year-old Asian man was driving a passenger car when he had a head-on collision with a dump truck and received an emergency call. He was transported to our hospital in a doctor's helicopter. Physical examination revealed the following vital signs: respiratory rate, 23 breaths per minute; $\mathrm{SpO}_{2}, 98 \%$ under a $10 \mathrm{~L}$ administration mask; pulse rate, 133 beats per minute; blood pressure, 142/128 mmHg; Focused Assessment with Sonography for Trauma, positive; Glasgow Coma Scale E3V5M6; and body temperature, $35.9^{\circ} \mathrm{C}$.

Trauma pan-scan CT showed bilateral mandibular fractures, bilateral multiple rib fractures, bilateral pneumothorax, sternal fractures, peri-thoracic hematoma, small bowel perforation, mesenteric injury, right clavicle fracture, right ankle debridement injury, and thrombotic occlusion of the bilateral common iliac arteries from just above the abdominal aortic bifurcation. Although thrombotic occlusion needed to be differentiated from traumatic aortic injury, the presence of collateral blood vessels led to the diagnosis of Leriche syndrome, and conservative treatment was performed.

Damage control surgery was required for small bowel injuries. From the second day of admission, the patient was treated with continuous intravenous heparin and prostaglandin preparations. However, impaired blood flow and reperfusion injury in the right lower extremity progressed. On the fifth day of admission, right thigh amputation was performed. The patient required renal replacement therapy for approximately two weeks starting from the third day of admission.

\section{Conclusions:}

In this case, conservative therapy was initially chosen as the treatment for Leriche syndrome. However, the complex factors in the acute phase of trauma lead to hemorrhagic necrosis development, resulting in amputation of the lower extremity. Our findings making necessitate the importance of decision of treatment indication and choice.

\section{Background}

Leriche syndrome is a progressive atherosclerotic disease affecting the abdominal aorta and iliac arteries. The risk factors for this syndrome include hypertension, hyperglycemia, hyperlipidemia, nicotine, age, male sex, and family history. The classic clinical presentation is bilateral buttock claudication, 
decreased femoral pulse, and sexual dysfunction. Because occlusion occurs due to disease progression, effective collateral pathways develop with time [1]. Therefore, it is a rare and chronic disease wherein patients are often asymptomatic, and its exact prevalence and incidence are unknown [2]. To the best of our knowledge, there are only few reports of Leriche syndrome diagnosed after a trauma.

In this study, we report a case of Leriche syndrome due to multiple trauma, diagnosed incidentally on computed tomography (CT).

\section{Case Presentation}

The patient was a 60-year-old Asian man without any symptoms such as intermittent claudication before the injury. The patient had a head-on collision with a dump truck while driving a passenger car. Approximately one hour after the injury, he was transported to our hospital in a helicopter with a physician onboard. On physical examination upon arrival, the patient had the following vital signs: respiratory rate, 23 breaths/min; $\mathrm{SpO}_{2}, 98 \%$ under a $10 \mathrm{~L} / \mathrm{min}$ administration mask; pulse rate, 133 breaths/min; blood pressure, 142/128 mmHg; Glasgow Coma Scale E3V5M6; and body temperature, 35.9 ${ }^{\circ} \mathrm{C}$. The Focused Assessment with Sonography for Trauma result was positive in Morrison's fossa and perisplenium, and his hemodynamic status was approximately 1.0 on the shock index. We started an incompatible blood transfusion $7 \mathrm{~min}$ after arrival. We suspected intra-abdominal bleeding based on the mechanism of injury and physical examination findings. Trauma pan-scan CT was performed 12 minutes after arrival to the hospital, and there were findings of small bowel injury and mesenteric injury together with intra-abdominal bleeding, which required damage control surgery (DCS).(Figure 1) Laboratory blood test data on admission are shown in Table 1. There was mild peripheral circulatory failure and renal dysfunction, but other values did not indicate any progression of anemia or coagulopathy at this time. DCS was started in the emergency department (ED) 42 minutes after arrival and was performed by opening the abdomen by crash laparotomy. As there was massive bleeding in the abdominal cavity, a five-point packing with suction was performed. The mesentery was lacerated $210 \mathrm{~cm}$ from the ligament of Treitz, and an incomplete tear of the small intestine was found in the same area; however, the liver and spleen showed no obvious damage. Active bleeding was observed from the mesenteric laceration site, and bleeding was sutured at the mesenteric edge. The injured part of the small intestine was cut using a linear cutter. There was no notable hematoma in the retroperitoneum. After confirming that there was no bleeding, the operation was completed in 48 minutes as open abdominal management (OAM) using vacuum packing closure without gastrointestinal reconstruction. The patient was then admitted to the acute critical care center.

Table 1 Laboratory findings on admission 


\begin{tabular}{|c|c|c|c|c|c|}
\hline$<$ Complete blood cell counts $>$ & & & $<$ Biochemistory $>$ & & \\
\hline White blood cells & 22,310 & $/ \mu \mathrm{L}$ & Total protein & 5.7 & $\mathrm{~g} / \mathrm{dL}$ \\
\hline Red blood cells & $416 \times 10^{4}$ & $/ \mu \mathrm{L}$ & Alibumin & 3.5 & $\mathrm{~g} / \mathrm{dL}$ \\
\hline Hemoglobin & 12.5 & $\mathrm{~g} / \mathrm{dL}$ & Aspartate transaminase & 84 & $\mathrm{IU} / \mathrm{L}$ \\
\hline Platelet & $196 \times 10^{3}$ & $/ \mu \mathrm{L}$ & Alanine transaminase & 64 & $\mathrm{IU} / \mathrm{L}$ \\
\hline$<$ Coagulation Status $>$ & & & Lactate deydrogenase & 341 & $\mathrm{IU} / \mathrm{L}$ \\
\hline $\begin{array}{l}\text { Activated partial } \\
\text { thromboplastin time }\end{array}$ & 26.2 & sec & Alikaline phosohatase & 223 & $\mathrm{IU} / \mathrm{L}$ \\
\hline $\begin{array}{l}\text { Prothrombin time-international } \\
\text { normalized ratio }\end{array}$ & 0.97 & & Creatinine & 1.47 & $\mathrm{mg} / \mathrm{dL}$ \\
\hline Finbrinogen & 215 & $\mathrm{mg} / \mathrm{dL}$ & Blood urea nitrogen & 24.1 & $\mathrm{mg} / \mathrm{dL}$ \\
\hline Fibrin degradation product & 104.6 & $\mu \mathrm{g} / \mathrm{mL}$ & Total bilirubin & 0.4 & $\mathrm{mg} / \mathrm{dL}$ \\
\hline D-dimer & 35.1 & $\mu \mathrm{g} / \mathrm{mL}$ & Sodium & 138 & $\mathrm{mEq} / \mathrm{L}$ \\
\hline <Arterial Blood Gas $>$ & & & Potassium & 4 & $\mathrm{mEq} / \mathrm{L}$ \\
\hline $\mathrm{FiO}_{2}$ & 1 & & Chloride & 106 & $\mathrm{mEq} / \mathrm{L}$ \\
\hline $\mathrm{pH}$ & 7.444 & & C-reactive protein & 0.02 & $\mathrm{mg} / \mathrm{dL}$ \\
\hline $\mathrm{PaCO}_{2}$ & 30.9 & $\mathrm{mmHg}$ & Blood sugar & 198 & $\mathrm{mg} / \mathrm{dL}$ \\
\hline $\mathrm{PaO}_{2}$ & 154 & $\mathrm{mmHg}$ & Haemoglobin A 1c & 5.6 & $\%$ \\
\hline $\mathrm{HCO}_{3-}$ & 20.8 & $\mathrm{mmol} / \mathrm{L}$ & & & \\
\hline Base Excess & -1.9 & & & & \\
\hline Lactate & 36 & $\mathrm{mg} / \mathrm{dL}$ & & & \\
\hline
\end{tabular}

The other imaging findings were bilateral mandibular fractures, bilateral multiple rib fractures, bilateral pneumothorax, sternal fracture, peri-thoracic hematoma, right clavicle fracture, right ankle debridement injury, and thrombotic occlusion of the bilateral common iliac arteries from just above the abdominal aortic bifurcation. The intraoperative findings of DCS in the ED showed no obvious suspicion of traumatic aortic injury, and a CT scan showed collateral blood vessels, leading to the diagnosis of Leriche syndrome, which is a chronic arterial occlusive disease. We tried to improve blood flow with intravenous alprostadil (Prostaglandin preparation) and continuous intravenous heparin administration.

Although we introduced acute renal replacement therapy to wash out creatinine kinase (CK) for acute kidney injury of grade 3 using the KDIGO criteria on day 3 , the elevated CK and myoglobin levels did not improve [3]. Open-abdominal management was completed on the same day. Furthermore, the findings of impaired blood flow in the right lower extremity gradually worsened. Contrast-enhanced CT of the lower extremities on day 4 showed heterogeneous hypoperfusion of the lower extremity muscles. Considering the patient's poor general condition, the right lower limb was amputated to save the patient's life on day 5 . Thereafter, each parameter of the blood test began to improve, and the patient's general condition improved. On day 14, he underwent tracheostomy after weaning from mechanical ventilation support on day 31 , and he was transferred to the general ward on day 43. Eventually, his rehabilitation progressed to the point where he was able to take up the standing position on parallel bars under supervision, and he was transferred to another hospital on day 80. 


\section{Discussion And Conclusions}

This report highlights the findings of a patient who was diagnosed with Leriche syndrome after severe multiple trauma, and we could save his life through multidisciplinary treatment including blood purification therapy and lower limb amputation. In this case, it was necessary to continue intermittent evaluation by frequent arterial palpation and Doppler measurement of the lower limbs during acute hemodynamic instability. Based on this experience, in the initial treatment strategy for trauma, even endogenous chronic diseases should be correctly and continuously evaluated, and flexible treatment strategies including early surgical intervention should be considered to improve the patient's quality of life after lifesaving.

Leriche syndrome, also commonly referred to as aortoiliac occlusive disease (AIOD), is a subset of peripheral arterial disease (PAD) and a complication of atherosclerosis affecting the distal abdominal aorta, iliac arteries, and femoropopliteal vessels [1]. AIOD is classified as embolism and thrombosis. In general, the frequency of thrombosis is $20-30 \%$, which is lower than that of embolism, and the patient may have intermittent claudication to begin with, followed by well-developed collateral circulation [4]. However, patients with PAD may be asymptomatic (10\%); therefore, the exact prevalence and incidence of Leriche syndrome are unknown. The prevalence of PAD increases in the aging population and is associated with other lifestyle-related diseases such as hypertension, diabetes mellitus, nicotine, hyperlipidemia, hyperglycemia, and homocysteine [2,5]. There are several cases of Leriche syndrome discovered after surgery or isolated trauma, but those discovered after multiple trauma are very rare. To the best of our knowledge, this is the first report on Leriche syndrome discovered after multiple trauma [6, 7].

AIOD is diagnosed using CT angiography or conventional angiography. The severity classification of acute lower limb arterial occlusive disease, similar to AIOD, is proposed in TASC II, as shown in Table 2 [8]. In category I, the patient did not require treatment. In category II, especially IIb, the patient required urgent revascularization, and in category III, the lesion could not be cured. (Figure 3 ) The standard therapy is intravenous unfractionated heparin [8]. Based on the results of randomized trials, there is no clear superiority between thrombolysis and surgery for 30-day limb salvage or mortality [9]. Although the revascularization approach that has shown better long-term results is the aortobifemoral bypass, the implementation of endovascular techniques has shown superior results, thereby reducing the surgical time, morbidity, and mortality in recent decades [10].

Table 2 Severity Classification of Acute Lower Limb Arterial Occlusive Disease 


\begin{tabular}{|c|c|c|c|c|c|}
\hline \multirow[t]{2}{*}{ Class } & \multirow[t]{2}{*}{ Description / Prognosis } & \multicolumn{2}{|l|}{ Findings } & \multicolumn{2}{|c|}{ Doppler signals } \\
\hline & & Sensory loss & $\begin{array}{l}\text { Muscle } \\
\text { weakness }\end{array}$ & Arterial & Venous \\
\hline$\rrbracket:$ Viable & $\begin{array}{l}\text { Not immediately } \\
\text { threatened }\end{array}$ & None & None & Audible & Audible \\
\hline \multirow{2}{*}{$\begin{array}{l}\mathbb{\text { }} \text { : } \\
\text { Threatened } \\
\text { a: Marginal } \\
\text { b: } \\
\text { Immediate }\end{array}$} & $\begin{array}{l}\text { Salvageable if promptly } \\
\text { treated }\end{array}$ & $\begin{array}{l}\text { Minimal (toes) or } \\
\text { none }\end{array}$ & None & $\begin{array}{l}\text { (Often) } \\
\text { inaudible }\end{array}$ & Audible \\
\hline & $\begin{array}{l}\text { Salvageable with } \\
\text { immediate } \\
\text { revascularization }\end{array}$ & $\begin{array}{l}\text { More than toes, } \\
\text { associated with } \\
\text { rest pain }\end{array}$ & $\begin{array}{l}\text { Mild, } \\
\text { moderate }\end{array}$ & $\begin{array}{l}\text { (Usually) } \\
\text { inaudible }\end{array}$ & Audible \\
\hline $\begin{array}{l}\text { 『: } \\
\text { Irreversible }\end{array}$ & $\begin{array}{l}\text { Major tissue loss or } \\
\text { permanent nerve } \\
\text { damage inevitable }\end{array}$ & $\begin{array}{l}\text { Profound, } \\
\text { anesthetic }\end{array}$ & $\begin{array}{l}\text { Profound, } \\
\text { paralysis } \\
\text { (rigor) }\end{array}$ & Inaudible & Inaudible \\
\hline
\end{tabular}

In our case, because the patient initially had no complaints of pain in the lower limbs and there was blood

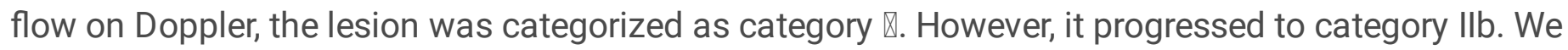
suggest that a combination of factors, such as decreased collateral blood flow and coagulopathy associated with hemorrhagic shock, possible accidental collateral blood vessel injury during DCS, and increased intra-abdominal pressure associated with laparotomy closure, may have triggered the exacerbation of Leriche syndrome. We tried to improve blood flow with alprostadil (Prostaglandin preparation) and continuous intravenous heparin administration. The blood flow deteriorated from the third day of hospitalization after the OAM was completed, but urgent revascularization was not possible because bypass surgery would have required revision of the abdomen, with a high risk of infection and bleeding, and endovascular treatment showed uncertain results in the acute phase of trauma. There were also concerns related to distal embolization. Consequently, the right lower limb was amputated on the fifth day. In hindsight, amputation may have been avoided if the OAM period had been prolonged with intensive care to stabilize the circulation and break out of the coagulopathy. The risk of suture failure increases when fascial sutures are performed after more than 5 days, and planned colostomy should be considered [6].

With the aging of the population in many countries, there is a possibility that the number of Leriche syndrome cases will increase, especially in elderly patients with traumatic injuries where aortoiliac occlusion is discovered incidentally or where PAD is present and worsens with difficulty in communication.

We believe that it is important not only to save the life of patients with severe multiple trauma but also to ensure their quality of life after treatment as much as possible. It is important to include the evaluation of chronic disease management over time as part of the treatment strategy in the acute phase of trauma. 


\section{Declarations}

\section{Ethics approval and consent to participate}

In Japan, approval from an ethics committee is not required for reporting of cases. This case was reported in accordance with the ethical guidelines for medical and health research involving human subjects established by the Japanese government.

\section{Consent for publication}

Written informed consent was obtained from the patient's legal guardians for publication of this case report and accompanying images. A copy of the consent form is available for the Editor-in-Chief of Scandinavian Journal of Trauma, Resuscitation and Emergency Medicine to review.

\section{Availability of data and materials}

The datasets used and/or analyzed during the current study are available from the corresponding author upon reasonable request.

\section{Competing interests}

The authors declare that they have no competing interests.

\section{Funding}

There are no sources of funding to declare.

\section{Authors' contributions}

GY, RK, KK, MI, T Miura, Y Kakino, H Oiwa, YM, RY, Y Kitagawa, TF, K Suzuki, T Miyake, H Okamoto, MT, NY, MS, NK, S Nagaya, S Nachi, MN, TD, H Okada, TY, K Shimabukuro, KK, SY, and SO participated in patient treatment. GY drafted the manuscript. RY revised and edited the manuscript. All authors have read and approved the final manuscript.

\section{Acknowledgements}

We would like to thank Editage (www.editage.com) for English language editing.

\section{References}

1. Pascarella $L$, Aboul Hosn M. Minimally invasive management of severe aortoiliac occlusive disease. J Laparoendosc Adv Surg Tech A. 2018;28:562-8.

2. Diehm C, Schuster A, Allenberg JR, Darius H, Haberl R, Lange S, et al. High prevalence of peripheral arterial disease and co-morbidity in 6880 primary care patients: cross-sectional study. Atherosclerosis. 2004;172:95-105. 
3. Khwaja A. KDIGO clinical practice guidelines for acute kidney injury. Nephron Clin Pract. 2012;120:c179-84.

4. Pramook M, Chanean R, Chumpol W, et al. Clinical differentiation between acute arterial embolism and acute arterial thrombosis of the lower extremities. J Med Assoc Thai. 2009 Jul;92(7):891-7.

5. Frederick M, Newman J, Kohlwes J. Leriche syndrome. J Gen Intern Med. 2010;25:1102-4.

6. Burlew CC, Moore EE, Cuschieri J, Jurkovich GJ, Codner P, Crowell K, et al. Sew it up! A Western Trauma Association multi-institutional study of enteric injury management in the postinjury open abdomen. J Trauma. 2011;70:273-7.

7. Lee BC, Oh DS, Lee HS, Kim SH, Park JH, Lee KH, et al. Leriche syndrome misdiagnosed as complex regional pain syndrome in a patient with neuropathic pain caused by a chip fracture: A case report. Medicina (Kaunas). 2021;57:486.

8. Norgren L, Hiatt WR, Dormandy JA, Nehler MR, Harris KA, Fowkes FG, et al. Inter-society consensus for the management of peripheral arterial disease (TASC II). Eur J Vasc Endovasc Surg. 2007;33:S175.

9. Berridge DC, Kessel DO, Robertson I. Surgery versus thrombolysis for acute limb ischaemia: initial management. Cochrane Database Syst Rev. 2002;3:Cd002784.

10. Rodríguez SP, Sandoval F. Aortoiliac occlusive disease, a silent syndrome. BMJ Case Rep. 2019;12:e230770.

\section{Figures}




\section{Figure 1}

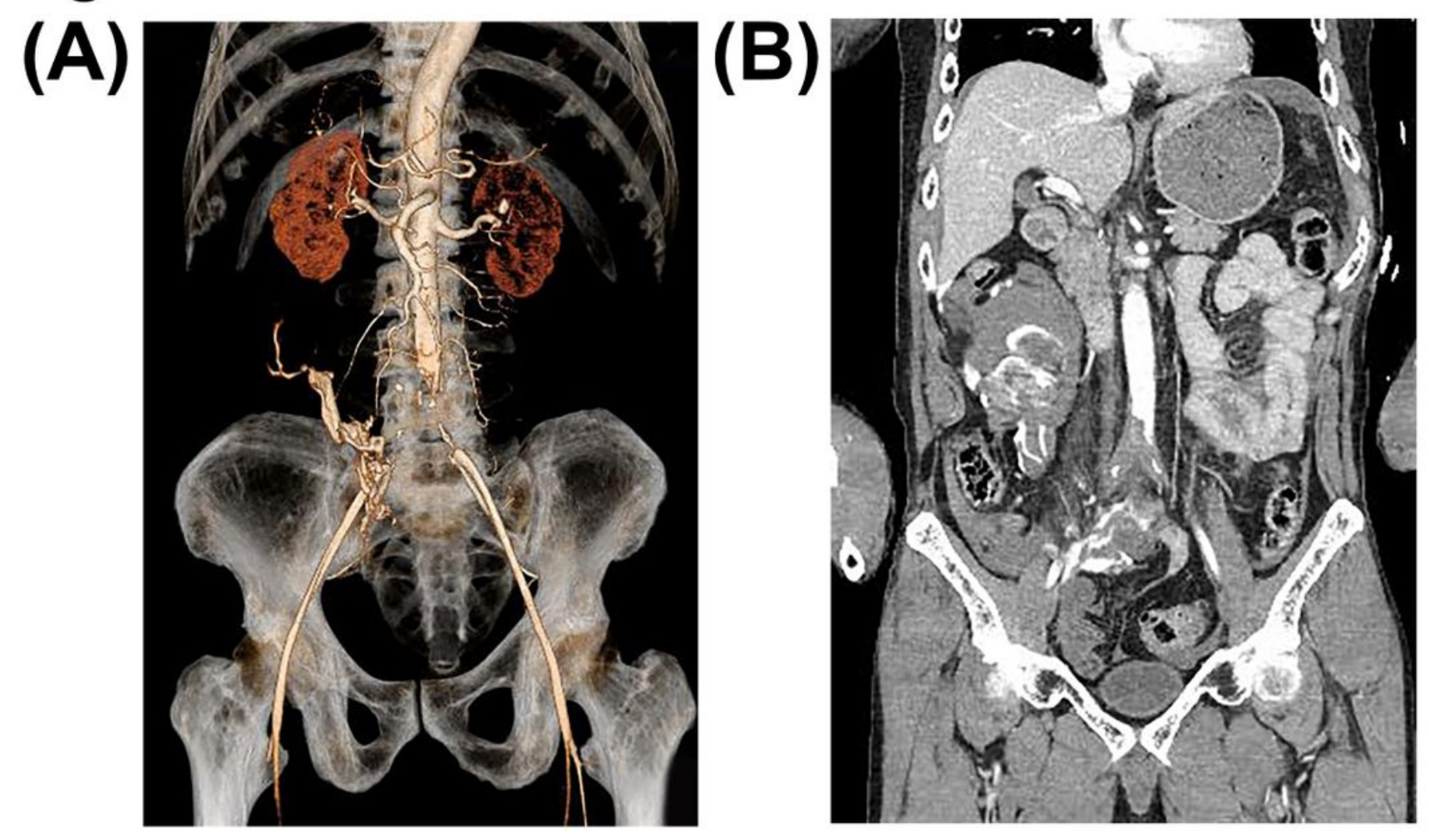

\section{Figure 1}

Title: Coronal computed tomographic (CT) reconstructions in arterial phase images. Legend (A) Complete occlusion just above the bifurcation of the abdominal aorta on 3D-CT image. In particular, the collateral blood pathway to the right external iliac artery can be seen. (B) Coronal contrast-enhanced CT images show disruption of blood flow due to thrombus at the aortic bifurcation and distal blood flow. 


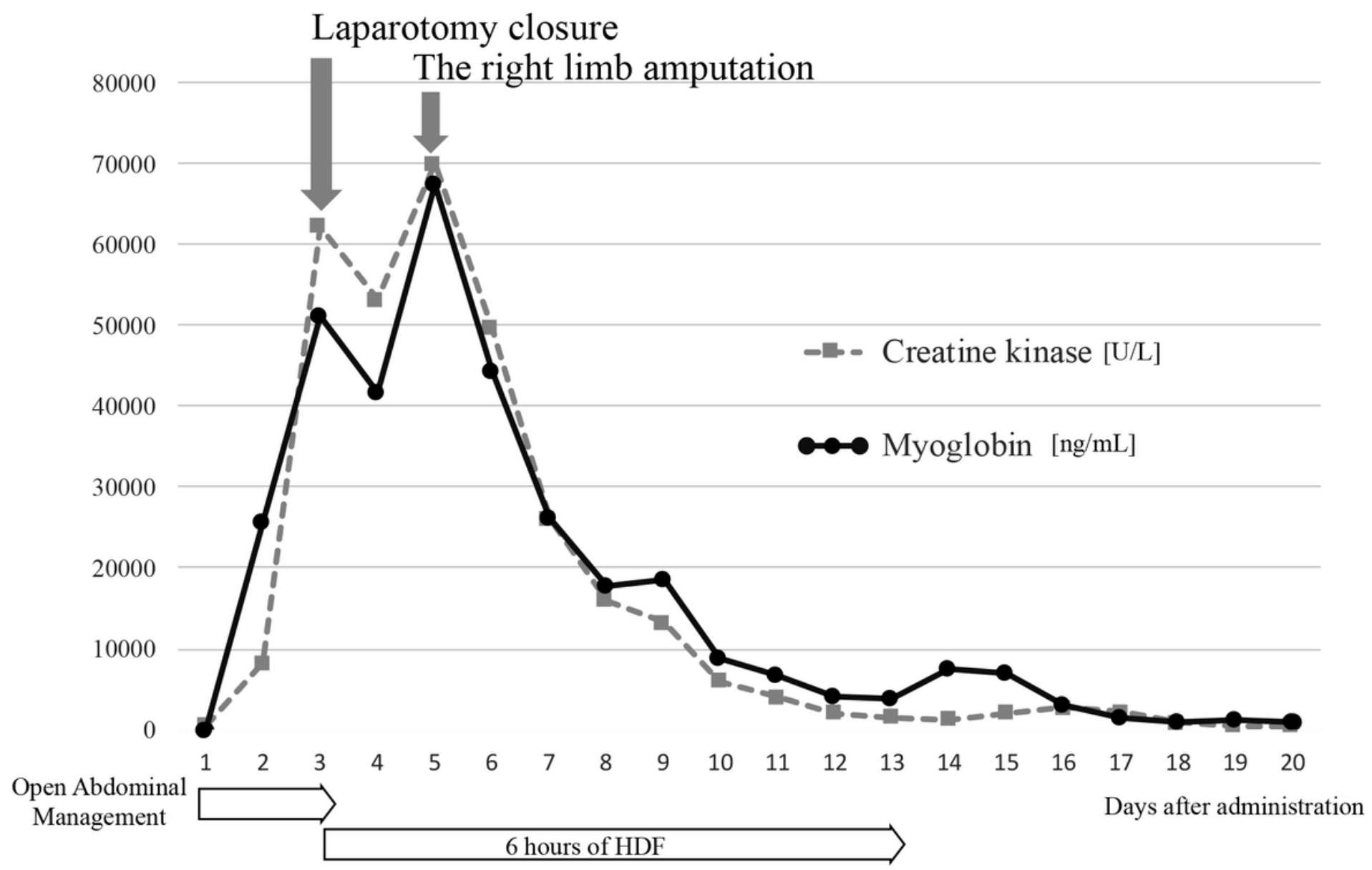

Figure 2

Title: Summary of the clinical course in the reported case. Legend Change in creatine kinase $(\mathrm{U} / \mathrm{L})$ and myoglobin $(\mathrm{ng} / \mathrm{mL})$ per days after admission. 


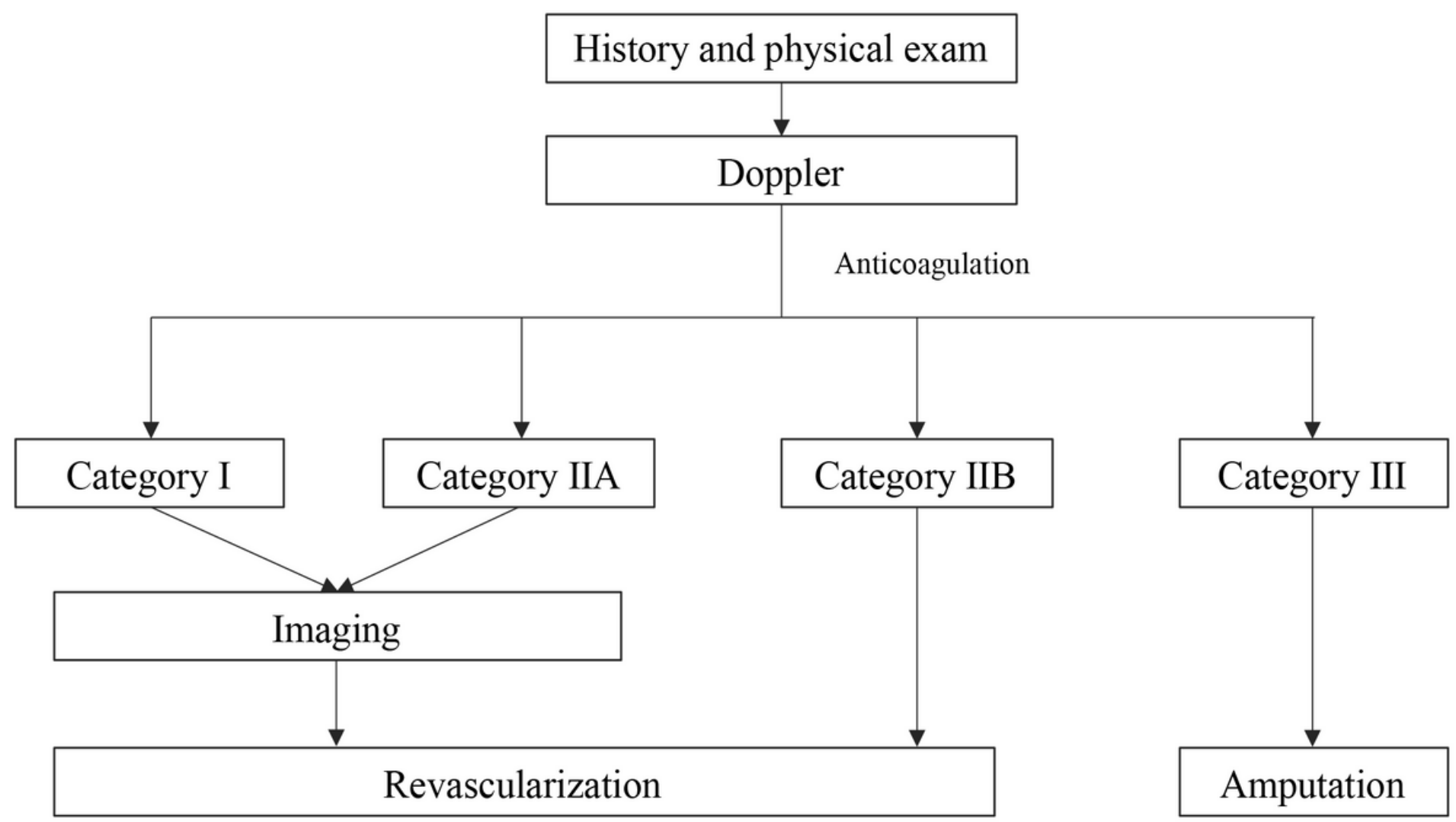

Figure 3

Title: Algorithm for the management of acute lower limb arterial occlusion Legend This algorithm was adapted from the Inter-society consensus for the management of peripheral arterial disease (TASC II) (Ref. 8). 